\title{
Corrosion Behavior of ZrCrMoNb High-entropy Alloy Coating in Ethylene Glycol Solution
}

\author{
Hanyang Zuo ${ }^{1,4}$, Long Wang ${ }^{4}$, Min Gong ${ }^{1,3^{*}}$, Xingwen Zheng ${ }^{2,3}$, Chunhai Liu ${ }^{4}$, Jinlong Fan ${ }^{1,3}$, \\ Feng Liu $^{1,3}$, \\ ${ }^{1}$ School of Material and Science Engineering, Sichuan University of Science \& Engineering, Zigong \\ 643000, China \\ ${ }^{2}$ School of Chemical and Environmental Engineering, Sichuan University of Science \& Engineering, \\ Zigong 643000, China \\ ${ }^{3}$ Key Laboratory of Material Corrosion and Protection of Sichuan Province, Zigong 643000, China \\ ${ }^{4}$ Southwestern Institute of Physics, Chengdu 610225, China \\ ${ }^{5}$ College of Materials and Chemistry \& Chemical Engineering, Chengdu University of Technology, \\ Chengdu 610225, China \\ *E-mail: gmsuse@126.com
}

doi: $10.20964 / 2021.01 .29$

Received: 4 September 2020 / Accepted: 10 November 2020 / Published: 30 November 2020

\begin{abstract}
A novel $\mathrm{ZrCrMoNb}$ high-entropy alloy coating was prepared on 3A21 aluminum alloy and its corrosion behavior in ethylene glycol solution was studied. By polarization curve, electrochemical impedance spectroscopy (EIS) and scanning electron microscope (SEM), the effects of temperature and concentration of ethylene glycol on corrosion behavior of $\mathrm{ZrCrMoNb}$ high-entropy alloy coatings were analyzed. The results show that the corrosion resistance of $\mathrm{ZrCrMoNb}$ high-entropy alloy coating degraded with the increase of temperature, and the corrosion current density of $\mathrm{ZrCrMoNb}$ high-entropy alloy coating in ethylene glycol solution decreases significantly when the V/V concentration ethylene glycol changes from $15 \%$ to $30 \%$, after that, the corrosion current density changed little with the increase of ethylene glycol concentration. Scanning electron microscope results display that the coating can improve the pitting corrosion resistance of 3A21 aluminum alloy in ethylene glycol solution.
\end{abstract}

Keywords: High-entropy alloy coating; ZrCrMoNb coating; Ethylene glycol solution; corrosion

\section{FULL TEXT}

(C) 2021 The Authors. Published by ESG (www.electrochemsci.org). This article is an open access article distributed under the terms and conditions of the Creative Commons Attribution license (http://creativecommons.org/licenses/by/4.0/). 